\title{
Manufacturer's Pricing Strategy for Supply Chain with Service Level-Dependent Demand
}

\author{
Cheng Qin, Tang Shu-yi
}

School of Management, University of Science and Technology of China, Hefei, People's Republic of China

\begin{abstract}
This article considers the pricing strategies of a manufacturer in a two-echelon supply chain with service leveldependent demand. This chain consists of one manufacturer and two retailers. The manufacturer decides the wholesale prices as a Stackelberg leader, and the retailers determine their service levels as the Stackelberg followers. We discuss the segmented and unified pricing strategies of the manufacturer. We also compute the optimal service levels and profits of the retailers, as well as the optimal wholesale prices and profits of the manufacturer associated with different pricing strategies. We conclude that the segmented pricing strategy benefits the manufacturer, whereas it cannot benefit the two retailers simultaneously. Furthermore, it is disadvantageous to the profit of the entire supply chain. Moreover, the increase in service cost coefficient adversely affects the earnings of the customers, the retailers, the manufacturer, and the entire supply chain. However, an increase in diffusion intensity benefits the customers, the manufacturer, and the supply chain.
\end{abstract}

Index Terms: Service level, pricing strategy, Stackelberg game, segmented pricing, unified pricing.

(C) 2014 Published by MECS Publisher. Selection and/or peer review under responsibility of the Research Association of Modern Education and Computer Science.

\section{Introduction and literature review}

With the development of the economy and the fierce market competition, the products of different companies are increasingly homogeneous, such that firms experience significant difficulties in profiting from traditional price competition alone. Gao (2000) discussed the price competition among some companies and concluded that companies should not simply initiate price competition to maximize profit. Instead, they should focus on product brand, quality, value-added service, and marketing or public relations. Specifically, service has become one of the most important factors in enhancing the competitive advantage of firms. Furthermore, an increasing number of supply chains rely on services and/or product quality to build brand loyalty and to avoid traditional price competition (Chen et al., 2012). Many companies have committed to providing high-level service to attract and to gain customers. For example, Lenovo Corporation occupies a large part of the computer market

`Corresponding author. Tel.: +86-0551-63602702

E-mail address: tangsy@ustc.edu.cn 
because of its satisfying post-sales performance. The Faw-Volkswagen Corporation has become a well-known motor corporation because it emphasizes the satisfaction and reputation of customers. We label this type of market demand as service level-dependent demand. The aforementioned service may also include free delivery, warranty, post-sales, and other services.

Many studies in the theoretic research field have discussed price competition, including Jaskold Gabszewicz and Thisse (1979), Singh and Vives (1984), Choi (1991), Buccola and VanderZanden (1997), Chen and Xiao (2012). Many authors also examined nonprice competition. Iyer (1998) analyzed how manufacturers should coordinate distribution channels under the conditions of the price and important nonprice competition of retailers. Nonprice factors may include the provision of product information, free repair, or after-sales service. Tsay and Agrawal (2000) investigated a distribution system in which two retailers directly compete for end customers through service and retail price. Other examples are provided in the studies conducted by Bernstein and Federgruen (2007), Bernstein and Federgruen (2004), and Xiao and Yang (2008). These studies mainly focused on the price and nonprice competition among retailers. By contrast, we concentrate on the different pricing strategies of a manufacturer under the condition of the service level competition among retailers.

Recent studies highlight a new research direction in which market demand is affected by service levels rather than retail prices. The primary interest is in the competition among retailers, which shifts from price to service differentiation (Chen et al., 2012). When every retailer offers the same retail price, the one who provides a high service level certainly tops the competition. For instance, the price difference in the home appliances of GOME and SUNING, which are the two leading home-appliance retailers in China, is slight and negligible. Nevertheless, the total sales volume of the flat-screen TV of GOME is higher than that of SUNING and other appliance retailers because GOME provides a three-year warranty to customers. Chen et al. (2012) discussed the pricing strategies of a manufacturer in supply chain with a warranty period-dependent demand. We extend this information in the current study by investigating the service levels of retailers, on which warranty may exert a significant influence. We also consider the different forms of the demand function and of the profit functions of retailers from Chen et al.'s study.

This paper considers the pricing strategies of a manufacturer in a two-echelon supply chain that consists of one manufacturer and two retailers. We assume that the homogeneous products of different retailers are sold at the same price and that retailers attract customers only by providing high-level services. Our demand function applies service level alone as its independent variable, that is, service level-dependent market demand. We mainly study two manufacturer pricing strategies, namely, the segmented and unified pricing strategies. In this study, we intend to answer the following questions: (1) What are the optimal service levels of retailers, wholesale manufacturer prices, and profits under different pricing strategies? (2) Which pricing strategy should be adopted under various parameter conditions? (3) What is the effect of service cost coefficient and the diffusion intensity parameters on the optimal service levels and profits of retailers, on the profit of the manufacturer, and on the profit of the entire supply chain?

The remainder of this paper is organized as follows. In Section 2, we formulate the model and discuss the equilibrium pattern. In Section 3, we provide some numerical examples. In Section 4, we present the conclusions.

\section{Model description and discussion}

This study discusses a two-echelon supply chain that consists of one manufacturer and two competing retailers, as depicted in Fig. 1. We assume that the manufacturer plays the Stackelberg game with every retailer. The manufacturer decides the wholesale prices as a Stackelberg leader, and the retailers determine their service levels accordingly as the Stackelberg followers. The two retailers order products from the same manufacturer and then sell the products to the customers at the end market. We assume that the products of the two retailers are completely homogeneous and are sold at the same retail price $p$. Thus, customers decide to buy the product from a particular retailer based solely on the service levels of retailers. Every retailer commits to providing an optimal service level to attract more customers and to maximize profit. The manufacturer also 
aims to determine the optimal wholesale prices for the same purpose. The unit manufacturing cost is denoted by $m$. The retailers presumably set different sales costs because of their varied sales efficiencies. The unit sales cost of retailer $i$ is represented by $c_{i}$. Without loss of generality, we assume that the unit sales cost of Retailer 1 is lower than that of Retailer 2. That is, $c_{1}<c_{2}$.

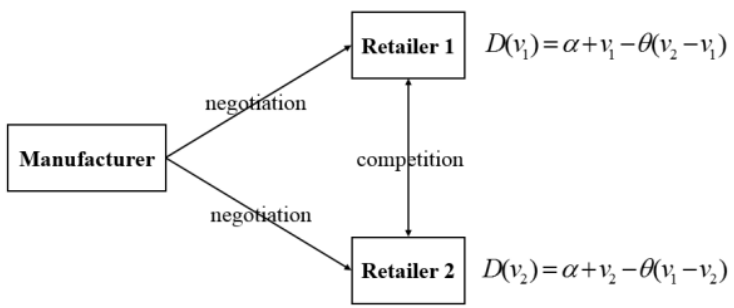

Fig. 1. Two-echelon supply chain with one manufacturer and two retailers.

We denote the service level of retailer $i$ as $v_{i}$. Retailer $i$ must spend $c\left(v_{i}\right)$, which is the service cost, to achieve level $v_{i}$. As in the studies of Iyer (1998), Tsay and Agrawal (2000), and Chen and Zhang (2013), we also formulate the convex service cost function as $c\left(v_{i}\right)=k v_{i}{ }^{2} / 2$, where $k>0$ is the service cost coefficient and measures the cost effectiveness of the service level. For convenient model deduction, we presume that the two retailers do not differ in terms of service cost coefficient and vary only with respect to unit sales cost.

Based on the studies conducted by Singh and Vives (1984) and Yao and Liu (2005), we define the demand function as follows:

$$
D\left(v_{i}\right)=\alpha+v_{i}-\theta\left(v_{j}-v_{i}\right),(i, j=1,2 \text {, and } i \neq j),
$$

where $\alpha$ is the market base and $\theta$ is the diffusion intensity, which describes the shift of customers between the two retailers. Moreover, we set $\theta>0$, which suggests that customers always shift away from a retailer that provides a low service level to one with a higher service level.

This study mainly considers two types of manufacturer pricing strategy:

Segmented pricing strategy (Pricing Strategy 1): The manufacturer negotiates with the two retailers separately based on sales costs and sets two different wholesale prices for the two retailers.

Unified pricing strategy (Pricing Strategy 2): The manufacturer negotiates with the two retailers simultaneously based on sales costs and sets a single wholesale price for both.

We discuss the two pricing strategies specifically in the following section. We appoint some marks prior to describing the model. In Strategy 1, we assume that the service level of retailer $i$ is $v_{1 i}$ and that the wholesale price of the manufacturer for retailer $i$ is $w_{1 i}(i=1,2)$. In Strategy 2, the service level of retailer $i$ is $v_{2 i}$ and the single wholesale price of the manufacturer is $w$.

\subsection{Segmented pricing strategy (Pricing Strategy 1)}

Under Pricing Strategy 1, the manufacturer first sets different wholesale prices $w_{11}$ and $w_{12}$ on Retailers 1 and 2 according to their various sales costs $c_{1}$ and $c_{2}$. Then, Retailer $i$ determines the optimal service level 
$v_{1 i}$ based on wholesale price $w_{1 i}$. We first consider the decision problem of the Stackelberg followers, that is, the retailers.

Retailer $i$ must identify the optimal service level $v_{1 i}$ to maximize profit. The objective function is given by

$\max \pi_{1 i}\left(v_{1 i}\right)=\left(p-w_{1 i}-c_{i}\right) D\left(v_{1 i}\right)-c\left(v_{1 i}\right)$

$$
=\left(p-w_{1 i}-c_{i}\right)\left(\alpha+v_{1 i}-\theta\left(v_{1 j}-v_{1 i}\right)\right)-\frac{k v_{1 i}^{2}}{2} \text {. }
$$

That is, each retailer must maximize the difference between total revenue and service cost. Following the discussion on objective function (2), we obtain the optimal service level $v_{1 i}^{*}$ of retailer $i$ and present it in the following proposition.

Proposition 1: Given Pricing Strategy 1, the optimal service level of retailer $i$ is $v_{1 i}^{*}=\frac{\left(p-w_{1 i}-c_{i}\right)(1+\theta)}{k}$.

Proof: We derive $\frac{d \pi_{1 i}\left(v_{1 i}\right)}{d v_{1 i}}=\left(p-w_{1 i}-c_{i}\right)(1+\theta)-k v_{1 i}$ and $\frac{d^{2} \pi_{1 i}\left(v_{1 i}\right)}{d v_{1 i}{ }^{2}}=-k<0$ from objective function (2), such that $\pi_{1 i}\left(v_{1 i}\right)$ is concave in $v_{1 i}$. If we let $\frac{d \pi_{1 i}\left(v_{1 i}\right)}{d v_{1 i}}=0$, then we can easily reach the conclusion.

The manufacturer must then determine different wholesale prices $w_{11}$ and $w_{12}$ with respect to Retailers 1 and 2 to maximize personal profit. The objective function is

$$
\max \pi_{1}^{m}\left(w_{11}, w_{12}\right)=\left(w_{11}-m\right) D\left(v_{11}^{*}\right)+\left(w_{12}-m\right) D\left(v_{12}^{*}\right) .
$$

Following a discussion on Eq. (3), we draw the following conclusion:

Proposition 2: Under Pricing Strategy 1, the optimal wholesale price of the manufacturer is $w_{1 i}^{*}=\frac{p+m-c_{i}(1+\theta)+\alpha k+m \theta+p \theta}{2(1+\theta)}$.

Proof: We derive $\frac{d v_{1 i}^{*}}{d w_{1 i}}=-\frac{1+\theta}{k}<0$, and $\frac{d^{2} v_{1 i}^{*}}{d w_{1 i}{ }^{2}}=\frac{d^{2} v_{1 i}^{*}}{d w_{1 i} d w_{1 j}}=0$ from Proposition 1. Then, we derive the following equations from Eq. (3):

$$
\begin{aligned}
& \frac{\partial \pi_{1}^{m}}{\partial w_{1 i}}=\alpha+v_{1 i}^{*}-\theta\left(v_{1 j}^{*}-v_{1 i}^{*}\right)+\left(w_{1 i}-m\right)(1+\theta) \frac{d v_{1 i}^{*}}{d w_{1 i}}-\left(w_{1 j}-m\right) \theta \frac{d v_{1 i}^{*}}{d w_{1 i}}, i, j=1,2, \\
& \frac{\partial^{2} \pi_{1}^{m}}{\partial w_{1 i}^{2}}=2(1+\theta) \frac{d v_{1 i}^{*}}{d w_{1 i}}<0, \frac{\partial^{2} \pi_{1}^{m}}{\partial w_{1 i} \partial w_{1 j}}=-\theta \frac{d v_{1 j}^{*}}{d w_{1 j}}-\theta \frac{d v_{1 i}^{*}}{d w_{1 i}}>0, i, j=1,2, i \neq j, \\
& \frac{\partial^{2} \pi_{1}^{m}}{\partial w_{11}{ }^{2}} \frac{\partial^{2} \pi_{1}^{m}}{\partial w_{12}{ }^{2}}-\frac{\partial^{2} \pi_{1}^{m}}{\partial w_{11} \partial w_{12}} \frac{\partial^{2} \pi_{1}^{m}}{\partial w_{12} \partial w_{11}}=4(1+2 \theta) \frac{(1+\theta)^{2}}{k^{2}}>0,
\end{aligned}
$$


such that $\pi_{1}^{m}\left(w_{11}, w_{12}\right)$ is concave. We can obtain the conclusion by setting $\frac{\partial \pi_{1}^{m}}{\partial w_{1 i}}=0$.

Based on Propositions 1 and 2, we can deduce that $w_{11}^{*}-w_{12}^{*}=\frac{c_{2}-c_{1}}{2}>0$ and $v_{11}^{*}-v_{12}^{*}=\frac{\left(c_{2}-c_{1}\right)(1+\theta)}{2 k}>0$. We thus compare the profits of the two retailers.

Proposition 3: Retailer 1 profits more than Retailer 2 using Pricing Strategy 1, that is, $\pi_{11}\left(v_{11}^{*}\right)>\pi_{12}\left(v_{12}^{*}\right)$.

Proof: From Propositions 1 and 2 and objective function (2), we derive the following equation:

$$
\begin{aligned}
& \pi_{11}\left(v_{11}^{*}\right)-\pi_{12}\left(v_{12}^{*}\right) \\
& =\left(p-w_{11}^{*}-c_{1}\right)\left(\alpha+v_{11}^{*}-\theta\left(v_{12}^{*}-v_{11}^{*}\right)\right)-\frac{k v_{11}^{* 2}}{2}-\left(p-w_{12}^{*}-c_{2}\right)\left(\alpha+v_{12}^{*}-\theta\left(v_{11}^{*}-v_{12}^{*}\right)\right)+\frac{k v_{12}^{* 2}}{2} \\
& =\frac{\left(c_{2}-c_{1}\right) \alpha}{2}+\frac{\left(c_{2}-c_{1}\right)(1+\theta)^{2}}{4 k}\left(\left(p-w_{11}^{*}-c_{1}\right)+\left(p-w_{12}^{*}-c_{2}\right)\right)>0 .
\end{aligned}
$$

The proof is thus completed.

\subsection{Unified pricing strategy (Pricing Strategy 2)}

In Pricing Strategy 2, the manufacturer first specifies a wholesale price $w$ for the two retailers based on their different sales costs $c_{1}$ and $c_{2}$. Then, Retailer $i$ decides his optimal service level $v_{2 i}$ according to $w$. We also consider the decision problem of the Stackelberg followers at first, that is, the retailers.

Retailer $i$ maximizes the difference between total revenue and total service cost. The objective function is expressed as follows:

$\max$

$$
\begin{aligned}
\pi_{2 i}\left(v_{2 i}\right) & =\left(p-w-c_{i}\right) D\left(v_{2 i}\right)-c\left(v_{2 i}\right) \\
& =\left(p-w-c_{i}\right)\left(\alpha+v_{2 i}-\theta\left(v_{2 j}-v_{2 i}\right)\right)-\frac{k v_{2 i}{ }^{2}}{2}
\end{aligned}
$$

Following an analysis of Eq. (8), we can determine the optimal service level of the retailers.

Proposition 4: Under manufacturer Pricing Strategy 2, the optimal service level of retailer $i$ is $v_{2 i}^{*}=\frac{\left(p-w-c_{i}\right)(1+\theta)}{k}$.

The proof is similar to that of Proposition 1. As such, we no longer detail it.

Then, we consider the decision problem of the manufacturer. The manufacturer must determine a wholesale price $w$ to maximize personal profit, which is expressed as follows:

$$
\max \pi_{2}^{m}(w)=(w-m)\left(D\left(v_{21}^{*}\right)+D\left(v_{22}^{*}\right)\right) .
$$

In the process of proving the concavity of the function in Eq. (9), we determine the optimal wholesale price of the manufacturer and present it in the following proposition. 
Proposition 5: Under Pricing Strategy 2, the optimal wholesale price of the manufacturer is $w^{*}=\frac{2 p+2 m-\left(c_{1}+c_{2}\right)(1+\theta)+2 \alpha k+2 m \theta+2 p \theta}{4(1+\theta)}$.

The proof is similar to that of Proposition 2. As such, we do not present it in detail any more.

Based on the optimal decisions of the retailers and of the manufacturer, we compare the profits of the two retailers under manufacturer Pricing Strategy 2.

Proposition 6: With Strategy 2, the profit of Retailer 1 is higher than that of Retailer 2, that is, $\pi_{21}\left(v_{21}^{*}\right)>\pi_{22}\left(v_{22}^{*}\right)$.

Proof: Since $v_{21}^{*}-v_{22}^{*}=\frac{\left(c_{2}-c_{1}\right)(1+\theta)}{k}>0$, then we derive the following equation:

$$
\begin{aligned}
& \pi_{21}\left(v_{21}^{*}\right)-\pi_{22}\left(v_{22}^{*}\right) \\
& =\left(p-w^{*}-c_{1}\right)\left(\alpha+v_{21}^{*}-\theta\left(v_{22}^{*}-v_{21}^{*}\right)\right)-\frac{k v_{21}^{* 2}}{2}-\left(p-w^{*}-c_{2}\right)\left(\alpha+v_{22}^{*}-\theta\left(v_{21}^{*}-v_{22}^{*}\right)\right)+\frac{k v_{22}^{* 2}}{2} \\
& =\left(c_{2}-c_{1}\right) \alpha+\frac{\left(c_{2}-c_{1}\right)(1+\theta)^{2}}{2 k}\left(\left(p-w^{*}-c_{1}\right)+\left(p-w^{*}-c_{2}\right)\right)>0 .
\end{aligned}
$$

Thus, the proof is completed.

As per propositions 3 and 6, we conclude that the profit of Retailer 1 is always higher than that of Retailer 2 regardless of the pricing strategy adopted by the manufacturer (either the segmented or the unified pricing strategies). This result is obtained based on the assumption that the unit sales cost of Retailer 1 is lower than that of Retailer 2, that is, $c_{1}<c_{2}$.

Based on Propositions 1, 2, 4, and 5, we can easily determine the following two corollaries. They are used to compare the two pricing strategies in the subsequent section.

Corollary 1: $w_{11}^{*}>w^{*}>w_{12}^{*}$ and $2 w^{*}=w_{11}^{*}+w_{12}^{*}$.

This corollary describes the relationship between the optimal wholesale prices of the manufacturer with the different pricing strategies. In Pricing Strategy 2, the manufacturer sets a lower price for Retailer 1 than that in Pricing Strategy 1 and a higher price for Retailer 2 than that in Pricing Strategy 1.

Corollary 2: $v_{11}^{*}<v_{21}^{*}, v_{12}^{*}>v_{22}^{*}$ and $v_{11}^{*}+v_{12}^{*}=v_{21}^{*}+v_{22}^{*}$.

This corollary shows the relationship between the optimal service levels of the two retailers with the two pricing strategies of the manufacturer. In Pricing Strategy 2, the manufacturer sets a low price for Retailer 1; thus, the optimal service level of Retailer 1 is higher than that in Pricing Strategy 1. By contrast, the manufacturer assigns a higher price to Retailer 2 under Pricing Strategy 2; thus, the optimal service level of Retailer 2 under this strategy is lower than that in Pricing Strategy 1.

\subsection{Segmented pricing strategy versus unified pricing strategy}

In this section, we discuss the effect of the two pricing strategies on the optimal profits of retailers, on the optimal profit of the manufacturer, and on the profit of the entire supply chain.

The following proposition compares the optimal profit of the manufacturer with the two different pricing strategies.

Proposition 7: $\pi_{1}^{m}\left(w_{11}^{*}, w_{12}^{*}\right)>\pi_{2}^{m}\left(w^{*}\right)$.

Proof: Based on Propositions 1, 2, 4, and 6, we derive the following equation: 


$$
\begin{aligned}
& \pi_{1}^{m}\left(w_{11}^{*}, w_{12}^{*}\right)-\pi_{2}^{m}\left(w^{*}\right) \\
& =\left(w_{11}^{*}-m\right)\left(\alpha+v_{11}^{*}-\theta\left(v_{12}^{*}-v_{11}^{*}\right)\right)+\left(w_{12}^{*}-m\right)\left(\alpha+v_{12}^{*}-\theta\left(v_{11}^{*}-v_{12}^{*}\right)\right) \\
& -\left(w^{*}-m\right)\left(\alpha+v_{21}^{*}-\theta\left(v_{22}^{*}-v_{21}^{*}\right)\right)-\left(w^{*}-m\right)\left(\alpha+v_{22}^{*}-\theta\left(v_{21}^{*}-v_{22}^{*}\right)\right) \\
& =\frac{\left(c_{2}-c_{1}\right)^{2}(1+\theta)(1+2 \theta)}{8 k}>0 .
\end{aligned}
$$

Therefore, the proof is completed.

This proposition shows that the manufacturer gains more from adopting Pricing Strategy 1 than from adopting Pricing Strategy 2. As such, the manufacturer should ideally choose Pricing Strategy 1, that is, the segmented pricing strategy. However, segmented pricing is based on the different sales costs of retailers, which are business proprietary information. The retailers prefer not to share this information with the manufacturer if their profits are lower under the segmented pricing strategy of the manufacturer than when under the unified pricing strategy. Therefore, we continue to analyze the effect of the two strategies on the optimal profits of the two retailers. We obtain:

$$
\begin{aligned}
& \pi_{21}\left(v_{21}^{*}\right)-\pi_{11}\left(v_{11}^{*}\right) \\
& =\left(p-w^{*}-c_{1}\right)\left(\alpha+v_{21}^{*}-\theta\left(v_{22}^{*}-v_{21}^{*}\right)\right)-\frac{k v_{21}^{* 2}}{2}-\left(p-w_{11}^{*}-c_{1}\right)\left(\alpha+v_{11}^{*}-\theta\left(v_{12}^{*}-v_{11}^{*}\right)\right)+\frac{k v_{11}^{* 2}}{2} \\
& =\frac{\left(c_{2}-c_{1}\right) \alpha}{4}+\frac{\left(c_{2}-c_{1}\right)(1+\theta)}{4 k}\left(\left(p-w^{*}-c_{1}\right)(1+\theta)+\frac{(5 \theta-1)\left(c_{2}-c_{1}\right)}{8}\right) ; \\
& \pi_{12}\left(v_{12}^{*}\right)-\pi_{22}\left(v_{22}^{*}\right) \\
& =\left(p-w_{12}^{*}-c_{2}\right)\left(\alpha+v_{12}^{*}-\theta\left(v_{11}^{*}-v_{12}^{*}\right)\right)-\frac{k v_{12}^{* 2}}{2}-\left(p-w^{*}-c_{2}\right)\left(\alpha+v_{22}^{*}-\theta\left(v_{21}^{*}-v_{22}^{*}\right)\right)+\frac{k v_{22}^{* 2}}{2} \\
& =\frac{\left(c_{2}-c_{1}\right) \alpha}{4}+\frac{\left(c_{2}-c_{1}\right)(1+\theta)}{4 k}\left(\left(p-w_{12}^{*}-c_{2}\right)(1+\theta)-\frac{(7 \theta+1)\left(c_{2}-c_{1}\right)}{8}\right) \\
& =\frac{\left(c_{2}-c_{1}\right) \alpha}{4}+\frac{\left(c_{2}-c_{1}\right)(1+\theta)}{4 k}\left(\left(p-w^{*}-c_{1}\right)(1+\theta)-\frac{(13 \theta+7)\left(c_{2}-c_{1}\right)}{8}\right) .
\end{aligned}
$$

We cannot directly assert the better pricing strategy of the two for every retailer because the differences in the optimal profits of every retailer under the two strategies, which are shown in Eqs. (12) and (13), are affected by the parameters of our model. Meanwhile, we can derive $\left[\pi_{21}\left(v_{21}^{*}\right)-\pi_{11}\left(v_{11}^{*}\right)\right]-\left[\pi_{12}\left(v_{12}^{*}\right)-\pi_{22}\left(v_{22}^{*}\right)\right]=\frac{\left(c_{2}-c_{1}\right)^{2}(1+\theta)(3+9 \theta)}{16 k}>0$, which suggests that the effect of the change in pricing strategy on Retailer 1 is stronger than that on Retailer 2. Furthermore, if $\pi_{12}\left(v_{12}^{*}\right) \geq \pi_{22}\left(v_{22}^{*}\right)$, then we certainly obtain $\pi_{21}\left(v_{21}^{*}\right)>\pi_{11}\left(v_{11}^{*}\right)$. By contrast, if $\pi_{21}\left(v_{21}^{*}\right) \leq \pi_{11}\left(v_{11}^{*}\right)$, then we have $\pi_{12}\left(v_{12}^{*}\right)<\pi_{22}\left(v_{22}^{*}\right)$. Therefore, if Pricing Strategy 1 benefits Retailer 2 more, then this strategy is disadvantageous to Retailer 1 . Moreover, if Pricing Strategy 1 benefits Retailer 1 more, then this strategy reduces the profit of Retailer 2. We have concluded that a manufacturer adopts Strategy 1 to increase profit; 
however, Strategy 1 does not benefit the two retailers simultaneously. The retailer whose profit is lower under the segmented pricing strategy than that under the unified pricing strategy will certainly not share his sales cost information with the manufacturer. In addition, if $\pi_{21}\left(v_{21}^{*}\right)>\pi_{11}\left(v_{11}^{*}\right)$ and $\pi_{12}\left(v_{12}^{*}\right)<\pi_{22}\left(v_{22}^{*}\right)$, then both retailers are inclined toward the unified pricing strategy (Strategy 2). Hence, both retailers do not share their cost information with the manufacturer.

In summary, the segmented pricing strategy of the manufacturer benefits the manufacturer. However, this strategy must be adopted under the condition of complete information, that is, the manufacturer knows the sales cost information of the two retailers. To maximize profit, not all retailers are willing to publicize their cost information. Therefore, the manufacturer may have to estimate or compute this sales cost using several approaches. If the estimation or computation cost alone is less than $\frac{\left(c_{2}-c_{1}\right)^{2}(1+\theta)(1+2 \theta)}{8 k}$ [see Eq. (11)], then ideally, the manufacturer should adopt the segmented pricing strategy.

We define the profit of the entire supply chain with different pricing strategies as follows:

$$
\begin{aligned}
& \pi_{1}^{w}=\pi_{1}^{m}\left(w_{11}^{*}, w_{12}^{*}\right)+\pi_{11}\left(v_{11}^{*}\right)+\pi_{12}\left(v_{12}^{*}\right), \\
& \pi_{2}^{w}=\pi_{2}^{m}\left(w^{*}\right)+\pi_{21}\left(v_{21}^{*}\right)+\pi_{22}\left(v_{22}^{*}\right) .
\end{aligned}
$$

These pricing strategies are compared in the following proposition.

Proposition 8: $\pi_{1}^{w}<\pi_{2}^{w}$.

Proof: Based on Proposition 7 and Eqs. (12), (13), and (14), we can obtain

$$
\begin{aligned}
& \pi_{1}^{w}-\pi_{2}^{w}=\pi_{1}^{m}\left(w_{11}^{*}, w_{12}^{*}\right)+\pi_{11}\left(v_{11}^{*}\right)+\pi_{12}\left(v_{12}^{*}\right)-\pi_{2}^{m}\left(w^{*}\right)-\pi_{21}\left(v_{21}^{*}\right)-\pi_{22}\left(v_{22}^{*}\right) \\
= & \frac{\left(c_{2}-c_{1}\right)^{2}(1+\theta)(1+2 \theta)}{8 k}-\frac{\left(c_{2}-c_{1}\right) \alpha}{4}-\frac{\left(c_{2}-c_{1}\right)(1+\theta)}{4 k}\left(\left(p-w^{*}-c_{1}\right)(1+\theta)+\frac{(5 \theta-1)\left(c_{2}-c_{1}\right)}{8}\right) \\
& +\frac{\left(c_{2}-c_{1}\right) \alpha}{4}+\frac{\left(c_{2}-c_{1}\right)(1+\theta)}{4 k}\left(\left(p-w^{*}-c_{1}\right)(1+\theta)-\frac{(13 \theta+7)\left(c_{2}-c_{1}\right)}{8}\right) \\
= & -\frac{\left(c_{2}-c_{1}\right)^{2}(1+\theta)(1+5 \theta)}{16 k}<0 .
\end{aligned}
$$

Thus, the proof is completed.

This proposition indicates that the profit of the entire supply chain is higher under the unified pricing strategy (Pricing Strategy 2) than under the segmented pricing strategy (Pricing Strategy 1). Given that segmented pricing should be adopted with the condition of complete information, then Proposition 8 implies that the profit of the entire supply chain given incomplete information is higher than that given complete information. Information sharing can increase the profit of the manufacturer, but it can reduce the profit of the entire supply chain. Thus, it certainly harms the profits of retailers.

\section{Numerical examples}

In this section, we analyze the effect of service cost coefficient $k$ and diffusion intensity $\theta$ on the optimal service levels and profits of retailers, on the profit of the manufacturer, and on the profit of the entire supply chain under different pricing strategies. We set $p=12, m=8, c_{1}=0.4, c_{2}=0.8, \alpha=10$. 


\subsection{Effect of service cost coefficient}

First, we discuss the effect of service cost coefficient and set diffusion intensity $\theta=0.4$. Fig. 2 shows the effect of service cost coefficient on the service levels of retailers. Fig. 3 and Fig. 4 depict the effect on profits.

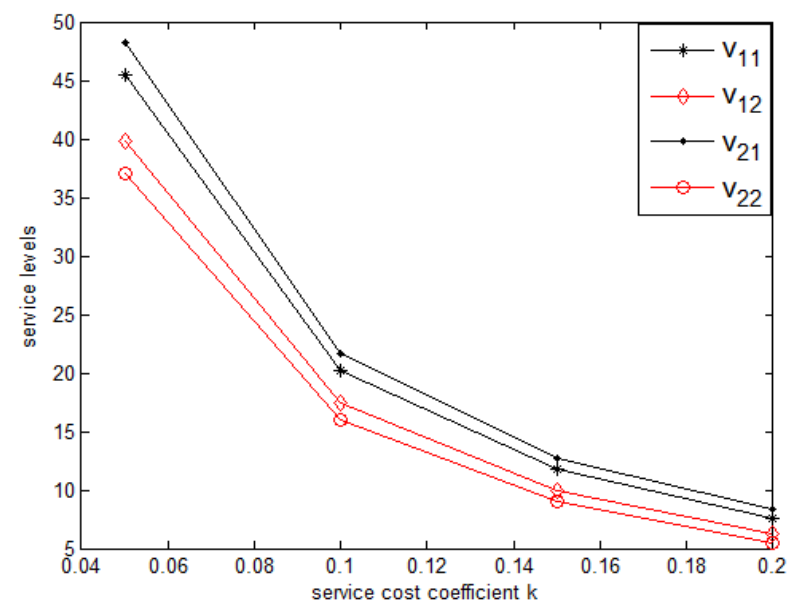

Fig. 2. Effect of service cost coefficient on optimal service levels.

Fig. 2 suggests that with the increase in service cost coefficient, the service levels $v_{11}, v_{12}, v_{21}, v_{22}$ of the two retailers all decrease under the two manufacturer pricing strategies. Thus, an increase in service cost coefficient is disadvantageous to customers.

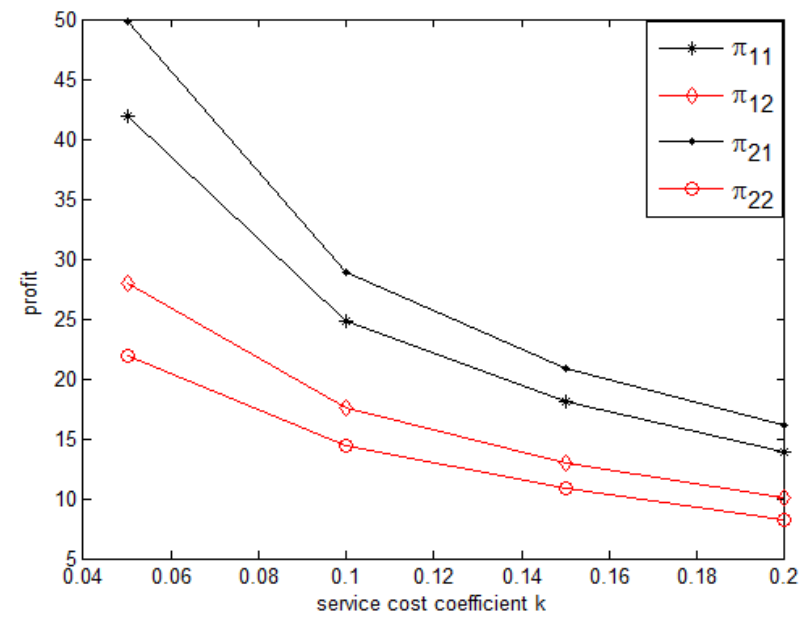

Fig. 3. Effect of service cost coefficient on the profits of retailers.

Fig. 3 indicates that with the increase in service cost coefficient, the profits of the two retailers all decrease under the two manufacturer pricing strategies. Moreover, the profit of Retailer $1\left(\pi_{11}, \pi_{21}\right)$ is higher than that 
of Retailer $2\left(\pi_{12}, \pi_{22}\right)$ under different pricing strategies. The profit of Retailer 1 in Strategy $2, \pi_{21}$, is higher than profit in Strategy $1, \pi_{11}$. However, the profit of Retailer 2 in Strategy 2, $\pi_{22}$, is lower than profit in Strategy $1, \pi_{12}$.

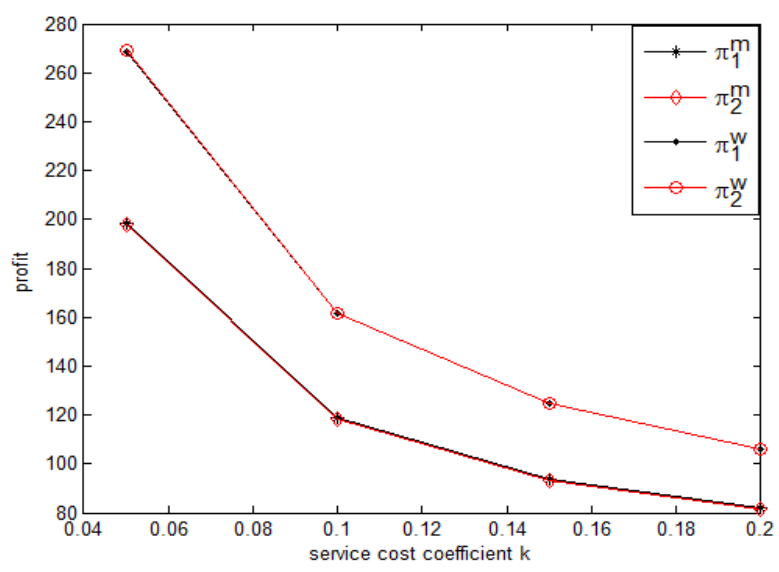

Fig. 4. Effect of service cost coefficient on the profits of the manufacturer and of the entire supply chain.

Fig. 4 illustrates that with the increase in service cost coefficient, the profits of the manufacturer and of the entire supply chain all decrease under the two pricing strategies.

In summary, the customers, the retailers, the manufacturer, and the entire supply chain are all adversely affected by an increase in service cost coefficient.

\subsection{Effect of diffusion intensity}

We continue to consider the effect of diffusion intensity and specify service cost coefficient $k=0.15$. Fig. 5 displays the effect of diffusion intensity on the service levels of retailers. Fig. 6 and Fig. 7 present the effect of diffusion intensity on profits.

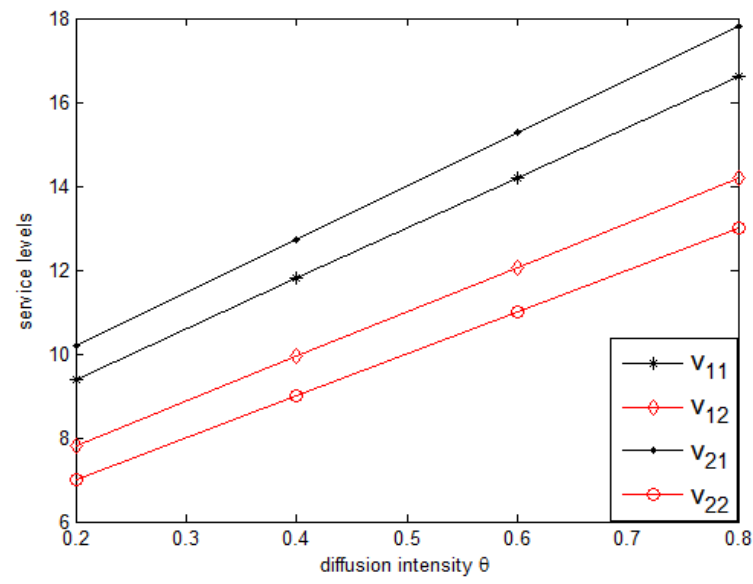

Fig. 5. Effect of diffusion intensity on optimal service levels. 


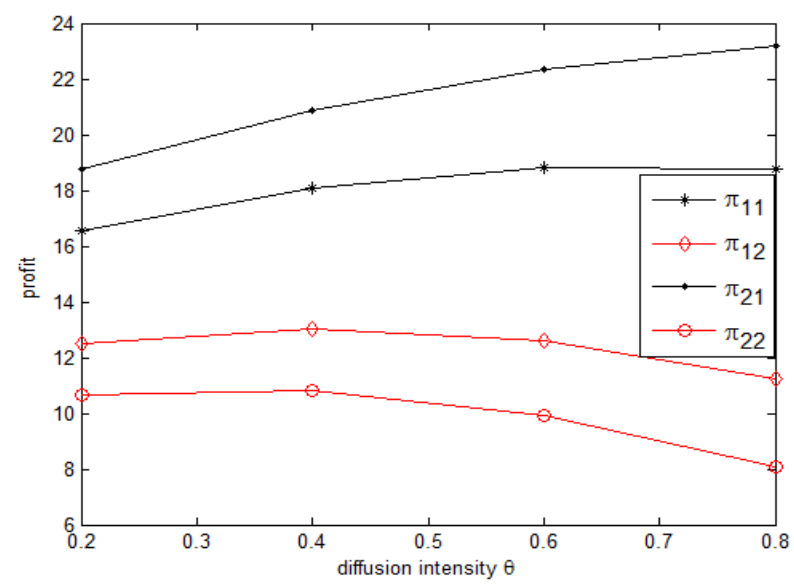

Fig. 6. Effect of diffusion intensity on the profits of retailers.

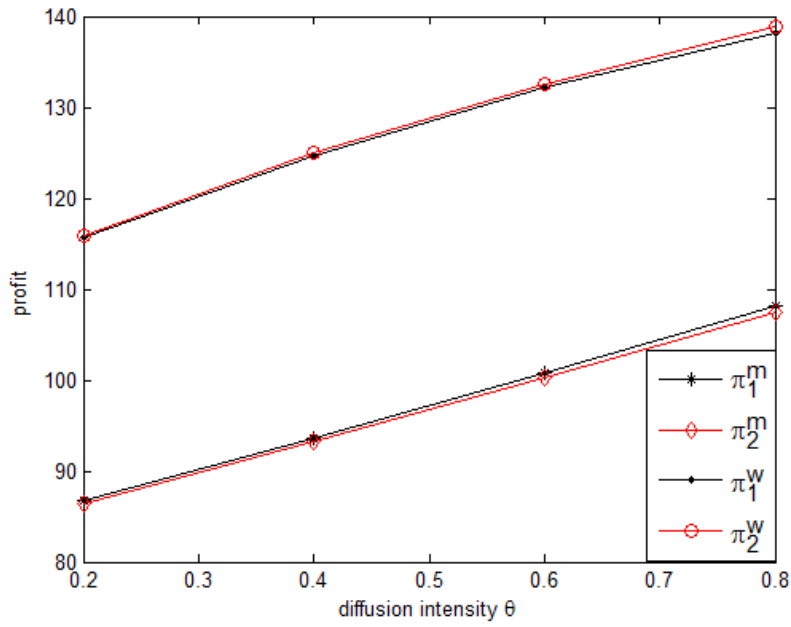

Fig. 7. Effect of diffusion intensity on the profits of the manufacturer and of the entire supply chain.

Fig. 5 indicates that with the increase in diffusion intensity, the service levels $v_{11}, v_{12}, v_{21}, v_{22}$ of the two retailers all increase under the two manufacturer pricing strategies. Thus, an increase in diffusion intensity benefits the customers.

Based on Fig. 6, the relationship among the optimal profits $\pi_{11}, \pi_{12}, \pi_{21}, \pi_{22}$ of retailers is maintained as that depicted in Fig. 3. However, the profits of retailers may increase or decrease with the increase in diffusion intensity.

Fig. 7 suggests that in the two pricing strategies, the profits of the manufacturer and of the entire supply chain all increase with the increase in diffusion intensity. Therefore, this increase benefits the manufacturer and the supply chain.

In summary, the customers, the manufacturer, and the entire supply chain all benefit from an increase in diffusion intensity. However, the profits of retailers may be either positively or negatively affected by this increase. 


\section{Conclusion}

This study considers a two-echelon supply chain that consists of one manufacturer and two retailers. The retail prices of the two retailers are presumably similar. The retailers commit to providing high-level service to attract customers and to increase revenue. The manufacturer decides the wholesale prices based on the sales costs of retailers as a Stackelberg leader, and the retailers decide their service levels as the Stackelberg followers based on their costs and the wholesale prices. Furthermore, we mainly discuss the segmented and unified manufacturer pricing strategies.

We compute the optimal service levels and profits of retailers and the optimal wholesale prices and profits of the manufacturer given the two different pricing strategies. We conclude that the segmented manufacturer pricing strategy benefits the manufacturer more, whereas it cannot benefit both retailers simultaneously. The retailer whose profit is lower with the segmented pricing strategy certainly will not share his sales cost information with the manufacturer. As a result, the manufacturer may have to estimate or compute this information using several approaches. We also set a cost limit; if the estimation or computation cost alone is less than the limit, then ideally, the manufacturer should adopt the segmented pricing strategy. Otherwise, the manufacturer should apply the unified pricing strategy. In addition, we confirm that the segmented manufacturer pricing strategy limits the profit of the entire supply chain.

We analyzed the effect of service cost coefficient and diffusion intensity on optimal service levels and on profits given different pricing strategies. We conclude that the customers, the retailers, the manufacturer, and the entire supply chain are all adversely affected by an increase in service cost coefficient. Moreover, an increase in diffusion intensity benefits the customers, the manufacturer, and the supply chain.

\section{References}

[1] Gao LB. The analyses of firms' pricing behavior patterns. Journal of Northwestern Polytechnical University, 2000, 20(4): 28-29.

[2] Chen X, Li L, Zhou M. Manufacturer's pricing strategy for supply chain with warranty period-dependent demand. Omega, 2012, 40(6): 807-816.

[3] Jaskold Gabszewicz J, Thisse J-F. Price competition, quality and income disparities. Journal of economic theory, 1979, 20(3): 340-359.

[4] Singh N, Vives X. Price and quantity competition in a differentiated duopoly. The RAND Journal of Economics, 1984, 546-554.

[5] Choi SC. Price competition in a channel structure with a common retailer. Marketing Science, 1991, 10(4): 271-296.

[6] Buccola ST, VanderZanden L. Wine demand, price strategy, and tax policy. Review of Agricultural Economics, 1997, 19(2): 428-440.

[7] Chen X-B, Xiao K. An Analysis on Price Dispersion in Online Retail Market Based on the Different of the Product Levels. International Journal of Engineering and Manufacturing, 2012, 2(4): 54-58.

[8] Iyer G. Coordinating channels under price and nonprice competition. Marketing Science, 1998, 17(4): 338-355.

[9] Tsay AA, Agrawal N. Channel dynamics under price and service competition. Manufacturing \& Service Operations Management, 2000, 2(4): 372-391.

[10] Bernstein F, Federgruen A. Coordination mechanisms for supply chains under price and service competition. Manufacturing \& Service Operations Management, 2007, 9(3): 242-262.

[11] Bernstein F, Federgruen A. A general equilibrium model for industries with price and service competition. Operations research, 2004, 52(6): 868-886.

[12] Xiao T, Yang D. Price and service competition of supply chains with risk-averse retailers under demand 
uncertainty. International Journal of Production Economics, 2008, 114(1): 187-200.

[13] Chen X, Zhang J. Manufacturer's Pricing Strategy for Mixed Retail and E-tail Channels. System Sciences (HICSS), 2013 46th Hawaii International Conference on, IEEE, 2013, 4154-4162.

[14] Yao D-Q, Liu JJ. Competitive pricing of mixed retail and e-tail distribution channels. Omega, 2005, 33(3): 235-247.

\section{Authors' profiles}

Qin Cheng was born in Anqing, Anhui Province, China, on 1 October 1990. She is a Master's candidate in Management Science and Engineering at the University of Science and Technology of China (USTC, Hefei, China). She obtained her Bachelor's degree in Information and Computing Science at Anhui University (AHU, Hefei, China) in 2012.

Her current research interests are in supply chain and operation management.

Shuyi Tang was born in Chaohu, Anhui Province, China, in August 1962. He received his Master's degree in Management Engineering from Hefei University of Technology in 1988. Currently, he is an Associate Professor of the University of Science and Technology of China (USTC, Hefei, China) and the Vice Chairman of the EMBA (Executive Master of Business Administration) center of USTC.

He has edited three Chinese books, he has also assisted in editing several other books with a maximum of 600,000 words in total. He has published more than 10 papers and participated in 3 projects. He was listed among the Young and Middle-aged Backbone Teachers at the Provincial Level by Anhui Province Education Department and was twice-rated as an outstanding teacher at Hefei Economic and Technological Academy.

His current research interest is in management information systems.

How to cite this paper: Cheng Qin, Tang Shu-yi,"Manufacturer's Pricing Strategy for Supply Chain with Service Level-Dependent Demand", IJEM, vol.4, no.4, pp.1-13, 2014.DOI: 10.5815/ijem.2014.04.01 